\title{
Histologic and Biomolecular Similarities in Healing between Aneurysms and Cutaneous Skin Wounds
}

\author{
(D).R. Ayers-Ringler, (D) Z. Khashim, (D)Y.-H. Ding, DD.F. Kallmes, and (DR. Kadirvel
}

\begin{abstract}
SUMMARY: The poorly understood mechanisms of aneurysm healing contribute substantially to the pressing medical problem of coiled aneurysm recanalization. Using an established saccular aneurysm model, we developed an animal model system in rabbits to study aneurysm and skin wound healing concurrently in the same animal. We found treated aneurysm healing to be similar to skin wound healing both histologically and in biomarker gene and protein expression, but in a delayed fashion.
\end{abstract}

ABBREVIATIONS: GAPDH = glyceraldehyde phosphate dehydrogenase; $\mathrm{H} \& \mathrm{E}=$ hematoxylin-eosin; SMA1 = $\alpha$ smooth muscle actin; TGF $\beta 1=$ transforming growth factor $\beta$ 1; PDGF = platelet derived growth factor; VEGF = vascular endothelial growth factor

D espite wide use and considerable safety of endovascular coiling of intracranial aneurysms, the recurrence rate is high even with second-generation coils, ${ }^{1}$ partially due to a dearth of knowledge about healing mechanisms involved. ${ }^{2}$ Conversely, cutaneous wound healing is well-established. The 4 distinct-yet-overlapping stages of cutaneous wound healing (hemostasis, inflammation, proliferation, and remodeling) have been thoroughly described. ${ }^{3}$ Here we demonstrate that concurrent study, in the same research subjects, of endovascular-versus-cutaneous healing provides insight into deficiencies in the cellular, molecular, and humoral features in aneurysm healing, enabling elucidation of potential targets for improved outcomes.

\section{MATERIALS AND METHODS}

\section{Aneurysm Creation and Coil Embolization}

All procedures were approved by the Institutional Animal Care and Use Committee before study initiation. Elastase-induced saccular aneurysms were created at the origin of the right common carotid artery in 12 female New Zealand white rabbits. ${ }^{4}$ At least 3

Received March 13, 2019; accepted March 19.

From the Department of Radiology, Mayo Clinic, Saint Mary's Hospital, Rochester, Minnesota.

This work was supported by Mayo Clinic Radiology Research and R01 grant number NS076491.

Please address correspondence to Ramanathan Kadirvel, PhD, Mayo Clinic, Depart ment of Radiology, Saint Mary's Hospital, Alfred 9-446CAR, 1216 2nd St SW, Rochester, MN 55902; e-mail: kadir@mayo.edu

- Indicates open access to non-subscribers at www.ajnr.org

http://dx.doi.org/10.3174/ajnr.A6046 weeks later, aneurysms were treated with platinum coils. DSA was performed after embolization.

\section{Cutaneous Ear Wound Creation}

Immediately after aneurysm treatment, an ear skin defect was created on the ventral side of 1 ear using a $1-\mathrm{cm}$ stainless steel punch, ${ }^{5}$ with removal of skin down to the cartilage. Hemostasis was achieved with pressure, followed by occlusive dressing (TegaDerm; 3M, St. Paul, Minnesota). Ear wounds were assessed visually daily for healing and wound closure rate.

\section{Follow-Up Imaging and Tissue Harvest}

At days 1, 5, 14, and 30 (groups 1-4) following treatment, DSA was performed from a left femoral approach, and the animals were euthanized. The aneurysm, ear wound, and contralateral control tissues were harvested for histology or cut in 2 for biomolecular studies.

\section{Angiographic Analysis}

Aneurysm occlusions at follow-up were rated either stable or progressive, or recanalizated compared with posttreatment angiograms using the modified Raymond scale. ${ }^{6}$

\section{Histologic Analysis}

Formalin-fixed aneurysms were evaluated for the degree of neck tissue coverage. ${ }^{7}$ Following a modified histologic technique, aneurysms and ear wounds were sectioned and stained with hematoxylin-eosin (H\&E) or Masson Trichrome for collagen. A semiquantitative scoring for thrombus organization, neoepithelialization, inflammation, cellularity, and collagen 
Genes important in cutaneous wound healing

\begin{tabular}{|c|c|c|c|}
\hline Wound-Healing Phase & Time & Cell Types & Key Molecules \\
\hline Inflammation & 0 min to 6 days & $\begin{array}{l}\text { Platelets, monocytes, neutrophils, macrophages, } \\
\text { and T-lymphocytes }\end{array}$ & PDGF, TGF $\beta 1$, VEGF, CD86, CD206 \\
\hline Proliferation & $24 \mathrm{hr}$ to weeks & Fibroblasts, endothelial cells, keratinocytes & $\begin{array}{l}\text { TGF } \beta 1 \text {, VEGF, PDGF, MMP9, CD86, } \\
\text { CD206 }\end{array}$ \\
\hline Remodeling & 4 days to months & Fibroblasts & PDGF, TGF $\beta 1$, SMAl, CD206 \\
\hline
\end{tabular}
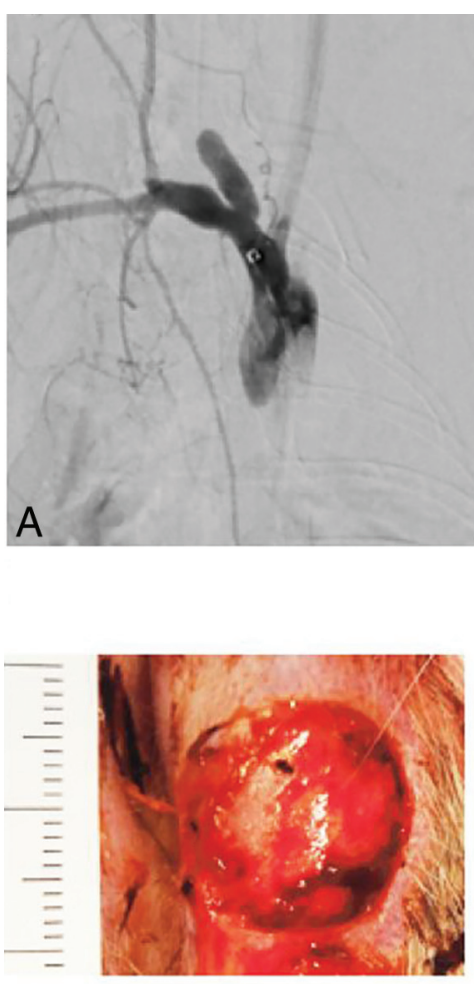

D
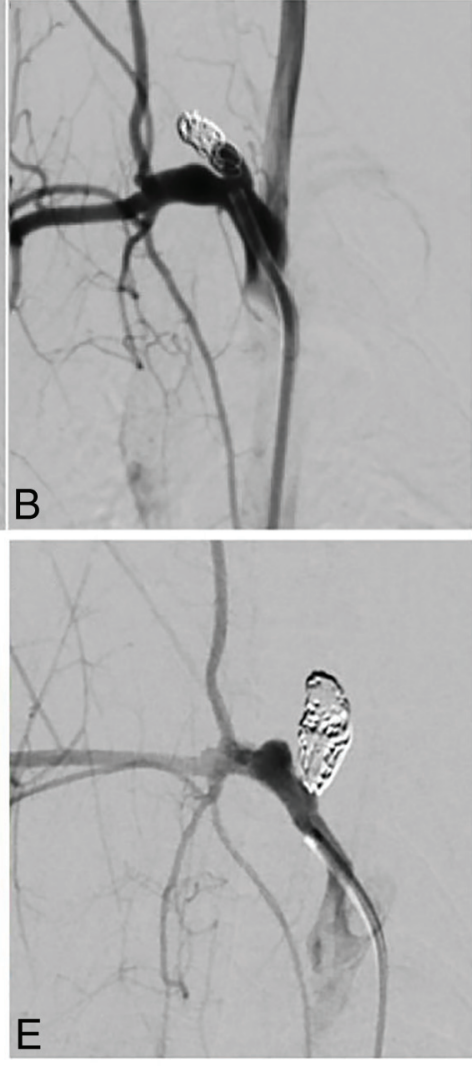

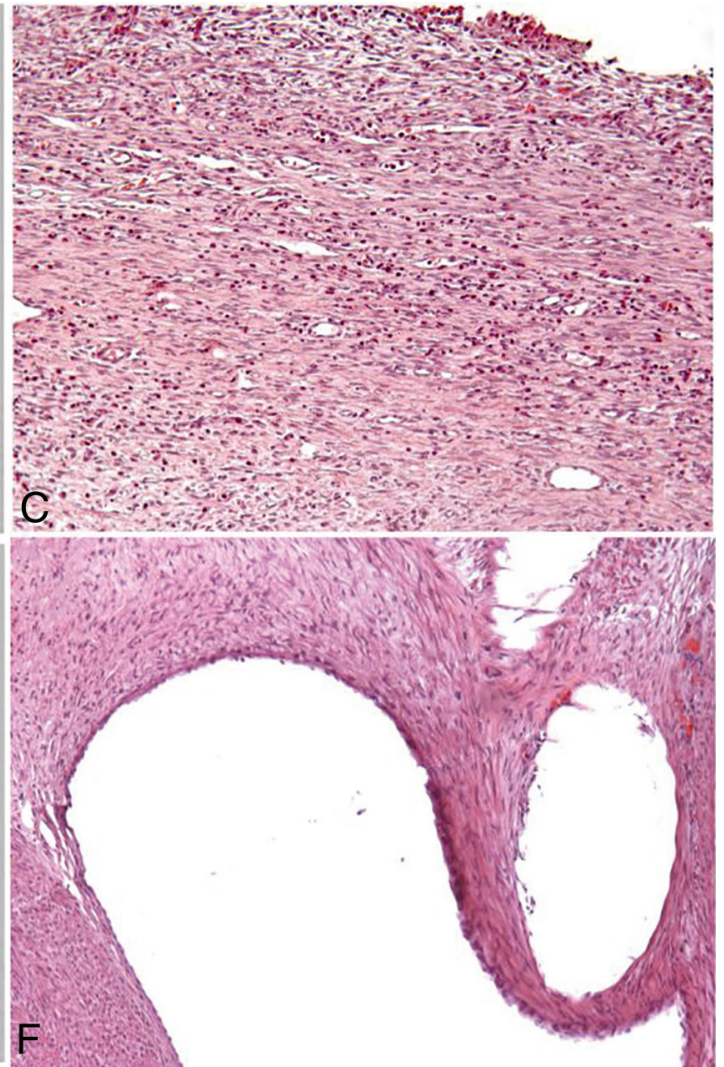

FIG 1. Angiograms with H\&E-stained tissue sections. Elastase-induced aneurysm $(A)$ on the day of platinum coil embolization and ear wound creation. Angiogram of coiled aneurysm at 14 days $(B)$ with a corresponding ear wound (C, H\&E, magnification $\times 100)$, macro image of the ear wound on day of sacrifice ( $D$, ruler markings are in centimeters, the smallest ticks in millimeters). Angiogram of 30-day coiled aneurysm ( $E)$ with corresponding aneurysm ( $F, \mathrm{H} \& \mathrm{E}$, magnification $\times 200)$. Note diffuse, dense myofibroblast (long, spindle-shaped) proliferation in both H\&E photomicrographs.

deposition was performed by a blinded reviewer. In addition, an ordinal grading system was used to evaluate histologic healing of aneurysms between groups.

\section{RNA Extraction and Expression Analysis by Real-Time Polymerase Chain Reaction}

Total RNA was isolated and converted to complementary DNA followed by real-time polymerase chain reaction with SYBR greenER (www.thermofisher.com). Target gene expression (Table) was normalized to glyceraldehyde phosphate dehydrogenase $(G A P D H)$ and reported as a fold change relative to control tissues (contralateral tissues) using the $2^{-\Delta \Delta \mathrm{Ct}}$ method.

\section{Protein Extraction and Analysis by Sodium Dodecyl Sulfate Polyacrylamide Gel Electrophoresis and Western Blot}

Soluble proteins were extracted from tissue samples with RIPA buffer (https://www.thermofisher.com/order/catalog/product/ 89900). Protein separation and western analysis were performed using a Wes system (ProteinSimple, San Jose, California). Protein expression data were normalized to control proteins (GAPDH or $\beta$-actin) using Compass Software (http://www.compasssoftware.de/en-us) and reported as fold change relative to control tissues.

\section{Statistical Analysis}

Continuous variables were compared using a Student $t$ test, and categoric variables were compared using the Fisher exact test.

\section{RESULTS}

\section{Aneurysm Angiography}

Among the first 3 groups, mean aneurysm neck, width, and height were $3.3 \pm 1.8 \mathrm{~mm}, 4.0 \pm 1.8 \mathrm{~mm}$, and $9.8 \pm 1.6 \mathrm{~mm}$, respectively. The aneurysms were completely occluded immediately after coil embolization in 11 of 12 cases (92\%), the other being incompletely occluded (8\%). Two of the 3 aneurysms in the 24 -hour 


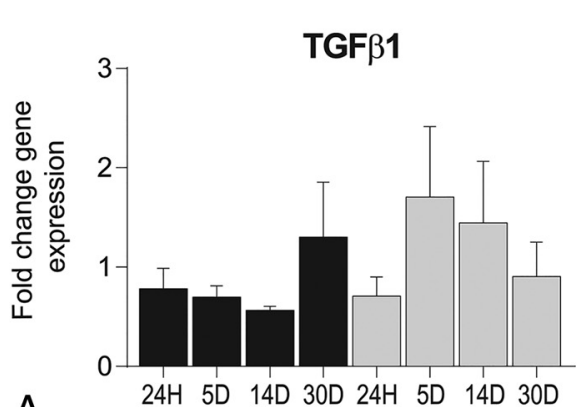

A
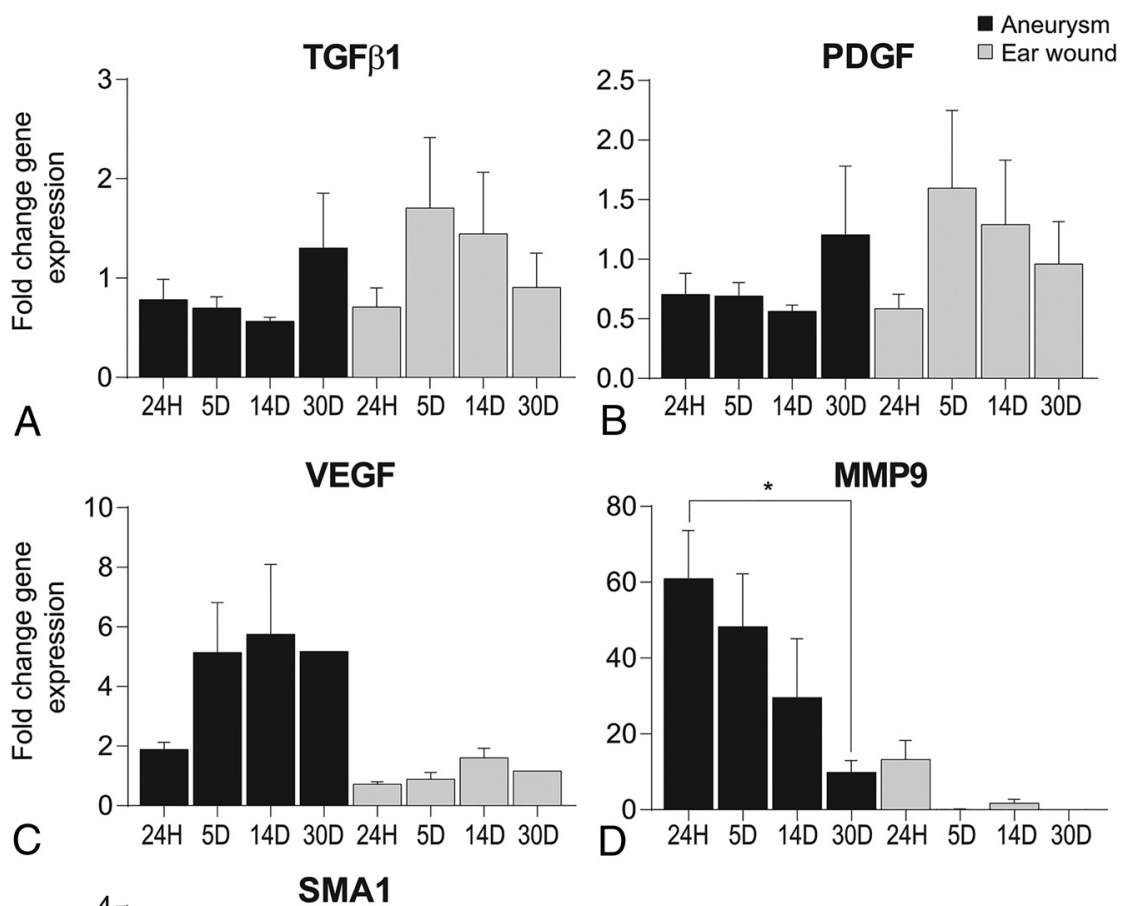

aneurysms were higher compared with ear wounds (Fig 2C, -D) and with inflammatory markers, overall. $\alpha$ smoothmuscle actin (SMA1) remodeling marker expressions were relatively unremarkable, with a small increase at 14 days in ear wounds (Fig 2E). Macrophage analysis showed an overall M1 polarization, with peak CD86 levels at 24 hours in aneurysms and 5 days in ear wounds (data not shown).

\section{DISCUSSION}

Our results reveal similarities and differences in wound-healing mechanisms for these 2 disparate environments. Histologically, skin wounds at 2 weeks resemble aneurysms at 1 month following platinum coil treatment, ${ }^{8}$ suggesting a roughly 2 -week healing delay in coiled aneurysms relative to skin wounds. Previous studies ${ }^{8}$ showed similar findings, supporting this issue of deficient immune cell infiltration and immunedriven healing mechanisms in platinum-coiled aneurysms. ${ }^{2}$ The biomolecular profiles reflect this healing delay and confirm an M1 polarization in the macrophage profile, indicating a deficient prohealing phenotype. ${ }^{9}$

\section{CONCLUSIONS}

This novel animal model enabling longitudinal study of platinum-coiled aneurysm healing in parallel with cutaneous wound healing provides an exceptional level of control and will

group, and 1 in the 14-day group showed recanalization at sacrifice. All the other aneurysms (9 of 12) remained completely occluded (75\%) (Fig 1).

\section{Histology}

Histologic analysis revealed necrosis and inflammatory cell infiltration in both epidermal and dermal layers of ear wounds at both 24 hours and 5 days, whereas scab formation in the epidermis and diffuse, dense cellular proliferation of myofibroblasts within the dermal layer with minimal inflammatory cells was found by 14 days. Aneurysm features were consistent with previous findings, ${ }^{8}$ with sparse myofibroblasts at the periphery of the aneurysm dome by 14 days, increasing dramatically by 30 days (Fig 1D, $-F$ ).

\section{Biomolecules}

Inflammatory marker gene expression was elevated at 5 days in ear wounds but reduced/delayed until 30 days in aneurysms (Fig $2 A,-B)$. Protein expression, however, was only 2 -fold for transforming growth factor $\beta 1$ (TGF $\beta 1$ ) at 24 hours and 30 days in ear wounds (data not shown). Proliferation marker expressions in help determine key signaling events necessary for proper arterial wound healing, promising development of improved treatments.

\section{ACKNOWLEDGMENTS}

We thank Chunfeng Zhao, MD, Praveen Kolumam Parameswaran, and Daiying Dai for essential work done for this article.

Disclosures: David F. Kallmes_UNRELATED: Stock/Stock Options: Superior Medical Experts, Comments: founder/shareholder. Ram Kadirvel—RELATED: Grant: National Institutes of Health, Comments: grant No. NS076491. * ${ }^{*}$ Money paid to the institution.

\section{REFERENCES}

1. Broeders JA, Ahmed Ali U, Molyneux AJ, et al. Bioactive versus bare platinum coils for the endovascular treatment of intracranial aneurysms: systematic review and meta-analysis of randomized clinical trials. J Neurointerv Surg 2016;8:898-908 CrossRef Medline

2. Brinjikji W, Kallmes DF, Kadirvel R. Mechanisms of healing in coiled intracranial aneurysms: a review of the literature. AJNR Am J Neuroradiol 2015;36:1216-22 CrossRef 
3. Baum CL, Arpey C. J. Normal cutaneous wound healing: clinical correlation with cellular and molecular events. Dermatol Surg 2005;31: 674-86; discussion 686 CrossRef Medline

4. Altes TA, Cloft HJ, Short JG, et al. 1999 ARRS Executive Council Award: creation of saccular aneurysms in the rabbit-a model suitable for testing endovascular devices. American Roentgen Ray Society. AJR Am J Roentgenol 2000;174:349-54 CrossRef Medline

5. Houdek MT, Wyles CC, Stalboerger PG, et al. Collagen and fractionated platelet-rich plasma scaffold for dermal regeneration. Plast Reconstr Surg 2016;137:1498-1506 CrossRef Medline

6. Raymond J, Salazkin I, Georganos S, et al. Endovascular treatment of experimental wide neck aneurysms: comparison of results using coils or cyanoacrylate with the assistance of an an- eurysm neck bridge device. AJNR Am J Neuroradiol 2002;23: 1710-16 Medline

7. Dai D, Ding H, Lewis DA, et al. A proposed ordinal scale for grading histology in elastase-induced, saccular aneurysms. AJNR Am J Neuroradiol 2006;27:132-38 Medline

8. Dai D, Ding YH, Kadirvel R, et al. A longitudinal immunohistochemical study of the healing of experimental aneurysms after embolization with platinum coils. AJNR Am J Neuroradiol 2006;27:736-41 Medline

9. Hoh BL, Hosaka K, Downes DP, et al. Monocyte chemotactic protein-1 promotes inflammatory vascular repair of murine carotid aneurysms via a macrophage inflammatory protein- $1 \alpha$ and macrophage inflammatory protein-2-dependent pathway. Circulation 2011;124:2243-52 CrossRef Medline 